\title{
Presentación del director
}

\author{
Alejandro Herrero-Olaizola / University of Michigan, Ann Arbor
}

Abrimos este número 56 de la revista con la fotografía "Tarde lluviosa en un día de cuarentena" de Juan David Caicedo Bernal, un instante de la pandemia en un lugar no identificado de Colombia que nos invita a pensar en la interrupción de nuestras formas y maneras de entender la cotidianeidad. Caicedo, en esta imagen, logra una llamativa composición cromática de un momento familiar, efímero y distante que evoca tiempos de calma y sosiego, ahora interrumpidos por la crisis global que estamos viendo. Tomando esta invitación visual a la reflexión, queremos compartir con nuestros lectores ese momento detenido, ese lapso temporal para adentrarnos en el amplio y variado contenido de este número de la revista. Fraguado durante la propia cuarentena que esta portada de Revista de Estudios Colombianos (REC) retrata, este número incluye una variedad de contribuciones que incluyen la musicología, los derechos humanos, el quehacer poético, la literatura marginal y periférica, la corrupción política y el recuerdo del conflicto en Colombia. Dichas temáticas (y otras adyacentes como la biopolítica y las diferencias socioeconómicas y raciales) se abordan a través de puntos de vista y acercamientos muy diversos y de temporalidades interseccionadas desde la época colonial hasta el siglo XXI.

REC 56 se inicia con el ensayo de Sergio Pérez Álvarez y Clara E. Herrera sobre la mujer neogranadina y su relación con el acceso a la cultura musical durante la Colonia. A través de un rastreo histórico muy detallado, los autores diseccionan el espacio lúdico de la música como un lugar para la consolidación de una subjetividad femenina que daría cuenta de la hibridación indígena, negra e hispana que rodeó el rol de las mujeres como consumidoras y practicantes de la música colonial. El carácter reivindicativo de esta contribución nos invita a repensar los roles tradicionales de las religiosas y otras mujeres como sujetos activos y creadores (y no simplemente como participantes pasivos) de la cultura musical durante los siglos XVI y XVII. Esta mirada novedosa y reivindicativa se atisba igualmente en el segundo ensayo de este número, a cargo de Alfredo Duplat y Andrés Molina Ochoa, quienes proponen leer el clásico de la literatura colombiana La vorágine (1924) dentro del contexto de impunidad y violación de derechos humanos que marcaría el trasfondo histórico de la novela. En este sentido, los autores detallan la relevancia del término fiction of distrust (ficción de desconfianza) para diseccionar la función social de esta novela en Colombia, que ellos ven como una narrativa que interviene para rechazar la impunidad estatal en zonas periféricas de la nación y como un archivo ficcional de la lucha contra dicha impunidad y del derecho a la verdad. Esa narrativa, argumentan Duplat y
Molina, se erige como una fuente privilegiada para reconocer los crímenes contra la humanidad y articular una lucha contra dichos crímenes.

Así como el segundo ensayo de este número plantea releer un texto literario canónico bajo la lente de los derechos humanos, el tercer ensayo propone leer otro clásico (más contemporáneo) con una nueva conceptualización del deseo femenino. Para Santiago Parga Linares, En Diciembre llegaban las brisas (1987) de Marvel Moreno es un texto que ha sido obviado por la crítica especializada y estudiado dentro de los patrones de la sexualidad femenina en el orden patriarcal. Este tipo de análisis, no obstante, obvia la importancia de otro tipo de deseo - el deseo por el conocimiento y la curiosidad intelectual - en el proceso de aprendizaje de la narradora protagonista de la novela. De este modo, el deseo por saber, por conocer, se antoja como el principio estructurador de la novela y como ejemplo de Bildungsroman que ilustra el crecimiento de la protagonista, su sexualidad y su relación con el poder. Al igual que este ensayo recupera a la escritora Marvel Moreno, en el cuarto ensayo de este número, Eliana María Urrego-Arango recupera la obra de Manuel Mejía Vallejo (1923-1998) a través de una mirada a la espacialidad creativa de Balandú - un espacio que nos remite a lugares como el Macondo de Gabriel García Márquez o el Comala de Juan Rulfo. Según Urrego-Arango, la espacialidad imaginaria y la poética de Balandú son claves en Mejía Vallejo para entender la temporalidad cíclica que marca los tiempos de la naturaleza en dichos espacios imaginarios, los cuales se rigen por la verticalidad espacial. Al estudiar el espacio de Balandú como una marca de la "novela total," este ensayo propone leer el universo literario de Mejía Vallejo como una "apuesta estética" del pensamiento andino.

El quinto ensayo del número, a cargo de Alejandra Rengifo, también se ocupa de la espacialidad, si bien el foco aquí es la periferia nacional de las islas de San Andrés y Providencia, vistas a través de la literatura de Lenito Robinson Bent. Para la autora, la prosa poética en la colección de relatos Sobre nupcias y ausencias (1988) de dicho autor se aleja del trasfondo histórico o político para dar paso a la melancolía, al espacio isleño, a la hibridación cultural, y a la reflexión sobre la muerte como ejes axiomáticos para entender las costumbres ancestrales de un archipiélago anacrónico e idílico donde moran los personajes. Mediante una mirada hacia la periferia, Rengifo propone examinar cómo se siente y se piensa dicho espacio híbrido como "una amalgama de las culturas de los primeros pobladores, los colonos ingleses, europeos, 
y los esclavos africanos" en el cual aún persiste la voluntad de "no ignorar la muerte, sino hacerla parte del vivir." Los márgenes nacionales y raciales que se vislumbran en esta contribución son también foco de estudio en el sexto ensayo de este número con la propuesta de Angie Carolina Mojica Sánchez para analizar la estratificación social y racial en Colombia. En concreto, Mojica estudia la segregación social y racial en la novela Los estratos (2013) de Juan Cárdenas a través de un acercamiento biopolítico que ilustra la estratificación socioeconómica como intervención poblacional y no individual; esto es, el estrato social entendido como parte de la implementación de programas públicos y de ordenamiento territorial por parte del estado. Dicho ordenamiento deviene una segregación que la obra de Cárdenas saca a la palestra al denunciar "el modo en que opera la noción de estrato asociada a la acentuación de una exclusión material y simbólica" y ofrecer una correlación entre la narrativa de ficción y la (bio) política.

Sin duda, el rol del estado y sus actuaciones políticas son elementos claves para los dos últimos ensayos de este número, que versan - a grandes rasgos - sobre la corrupción y el conflicto en Colombia. El ensayo de María Angélica Garzón y Diana Marcela Bernal se ocupa de la construcción del recuerdo en entornos regionales alejados de los parámetros oficialistas de centros de la memoria promovidos por entidades gubernamentales. A través de la oralidad y de la recreación rural de seres sobrenaturales como las brujas, las autoras examinan el caso de la Cuchilla de Buenavista (Lengupá, Boyacá) para ilustrar cómo brujas (y otras figuras legendarias como el Mohán) obligan a recordar y se antojan como portadoras de unos recuerdos circulares "que no cesan y dan cuenta de sus poderes para controvertir el pasado proponiendo futuros distintos y el rehacer del presente." Se trata de voces alternativas de la rememoración que, como ocurriera antaño, "filtran órdenes coloniales o de violencia armada" para desmontarlas desde sus conocimientos ancestrales y no desde estamentos oficiales. La crítica hacia dichos aparatos del estado colombiano es el centro de la discusión sobre la corrupción en el ensayo de Pamela Valencia Mosquera. En concreto, la autora examina las políticas neoliberales estatales que han dado como resultado la corrupción y el auge del populismo. Tomando como ejemplo la Consulta Anticorrupción de 2018 en Colombia, Valencia entiende la corrupción "como un acto que viola tanto las reglas de comportamiento y los recursos públicos, como los valores y principios de orden moral que todavía se conservan en las sociedades neoliberales," lo cual lleva irremediablemente a una despolitización de la corrupción y a un nuevo movimiento populista.

Además de estos ensayos, el número incluye una nota en homenaje al destacado académico Carlos Rincón
(1937-2018), quien tuviera una extensa trayectoria académica en Latinoamérica, Europa y Estados Unidos. Gracias al preciso recorrido que nos ofrece Alejandro Sánchez Lopera en esta nota, los lectores de la revista pueden (re)familiarizarse con los elementos más significativos en la obra académica de Rincón, los cuales - según Sánchez Lopera - tienen que ver con la crisis de la representación y sus preferencias por la unidad y la identidad. En este condensado y rico panorama de su obra crítica, se vislumbra el peso intelectual de Rincón y sus encuentros y desencuentros con varias corrientes del pensamiento latinoamericano contemporáneo. Este número se completa con la entrevista de Astrid Lorena Ochoa Campo a la escritora colombo-americana Ingrid Rojas Contreras, autora de la novela Fruit of the Drunken Tree (2018) - a la sazón ganadora de la medalla de plata del First Fiction (California Book Awards). La entrevista se contextualiza dentro de la diáspora colombiana y latinoamericana en Estados Unidos y ofrece el punto de vista de Rojas sobre la situación y las políticas migratorias más recientes.

Finalmente, ofrecemos en este número seis reseñas de libros que han tenido un importante impacto en el campo de los estudios colombianos recientemente, entre los cuales destacan El rompecabezas de la memoria de María Ospina, Managing Multiculturalism de Jean Jackson y Colombia: al borde del paraíso de Luca Zanetti. Esperamos que estas reseñas sean del agrado de nuestros lectores y aprovechamos esta oportunidad para invitarles a que continúen enviándonos obras para reseñar con el fin de actualizar nuestro listado en la plataforma digital. Agradecemos el trabajo de los reseñadores en este número-Rory O'Bryen, Andrés Velásquez, Alberto Berón, Camilo Malagón, Marcela Velasco y Ángela Robledo-, así como la labor de supervisión de nuestro Editor de Reseñas, Felipe Gómez. Igualmente, nuestro comité editorial-María Mercedes Andrade, Kevin Guerrieri, Héctor Hoyos, Chloe Rutter-Jensen, Víctor M. Uribe-Uran, Norman Valencia - así como nuestro asistente editorial (Martín Ruiz Mendoza) y diagramadora (Ana María Viñas) merecen un especial reconocimiento y agradecimiento por su tesón y dedicación al trabajo durante este tiempo convulso de la pandemia. Con este número 56 celebramos el sexto ejemplar de la revista en su nueva etapa digital y continuamos en nuestro esfuerzo para lograr una mayor difusión de Revista de Estudios Colombianos a través de nuestra plataforma digital, redes bibliográficas, académicas y sociales. Confiamos que el contenido de $R E C 56$ contribuya a la divulgación de los estudios colombianos y que los allegados de la revista logren encontrar en sus páginas el sosiego que anuncia la imagen de nuestra portada durante tiempos de cuarentena y pandemia. 